\title{
Construções de posse predicativa na língua Apurinã (Aruák)
}

\section{Predicative possession constructions in the Apurinã language (Arawak)}

\author{
Marília Fernanda Pereira de Freitas ${ }^{1}$, Sidney da Silva Facundes ${ }^{2}$
}

Doutoranda no Programa de Pós-graduação em Letras da Universidade Federal do Pará (Doutorado em Letras - Estudos Linguísticos). Professora Assistente da Faculdade de Letras (Curso de Graduação em Língua Portuguesa) na mesma instituição.

mfpf31@yahoo.com.br

Doutor em Linguística pela Universidade de Búfalo. Professor do Programa de PósGraduação em Letras da Universidade (ederal do Para e professor do Curso de
RESUMO: A presente pesquisa aborda as principais questões relativas à codificação linguística da posse em construç̃̃es verbais da língua Apurinã (Aruak), falada por várias comunidades indígenas espalhadas ao longo de diferentes tributários do rio Purus, sudeste do estado do Amazonas. Para tanto, parte-se das contribuições de alguns estudiosos que se ocupam em descrever a posse enquanto categoria linguística, no intuito de comparar o que se tem sobre esse assunto em termos tipológicos e o que se observa na língua Apurinã, em construções de posse predicativa. Assim, recorreuse a autores como Heine (2001), Perniss e Zeshan (2008) e Stassen (2009) para a caracterização tipológica e classificação do domínio da posse. Em se tratando da expressão de posse em Apurinã, apresenta-se um resumo da análise anteriormente feita por Facundes (1995 e 2000), para, então, apresentar novos dados e análises, com base em pesquisas de campo desenvolvidas em novembro de 2014 e abril de 2015 . Em Apurinã, a forma verbal awa, significando 'ter', ocorre em construções de posse predicativa, como em n-awa-ry epi kanawa, 'Eu tenho duas canoas' (em que $n$ - codifica a 1 a pessoa do singular; awa corresponde ao verbo 'ter'; -ry equivale à 3a pessoa do singular masculino objeto; epi significa 'dois' e kanawa corresponde à 'canoa'). Adicionalmente à forma $a w a$, na pesquisa de campo desenvolvida foram detectadas duas outras formas verbais nunca antes atestadas relacionadas à expressão de posse, as quais serão descritas neste artigo.

Palavras-CHAVE: Domínio da posse; Posse predicativa; Apurinã; Aruak

ABSTRACT: This research addresses the main issues concerning the ownership linguistic codification in verbal constructions of the Apurinã language (Arawak), spoken by many indigenous communities spreading over different tributaries of the Purus River in the southeastern state of Amazonas. It starts from the contributions of some scholars who are engaged in describing the possession as a language category, in order to compare the typological view of possession in linguistics with the expression of possession in the Apurinã language, specifically in terms of predicative possession We refer to authors such as Heine (2001), Perniss and Zeshan (2008) and Stassen (2009) for the typological characterization and classification of ownership domain. In the case of predicative possession expression in Apurinã, we present a summary of the analysis previously made by Facundes 1995 and 2000), to then present new data and analysis, based on field research conducted in November 2014 and March 2015. In Apurinã the awa verb, meaning 'have', occurs in predicative possession constructions, as in $n$-awa-ry epi kanawa, 'I have two canoes' (where $n$ - encodes the 1 st person singular; awa corresponds to the verb 'to have'; -ry is equivalent to 3rd person masculine singular object; epi means 'two' and kanawa corresponds to 'canoe'). In addition to $a w a$, we detected, during the field research, two other verbal forms never before attested related to the expression of possession in Apurinã, and which will be described in this article. We present, therefore, a review of the analysis previously done by Facundes (1995 and 2000), adding new data and analysis based on data from the most recent field survey.

KEYwoRDS: Ownership domain; Predicative possession; Apurinã; Arawak. 


\section{Introdução ${ }^{1}$}

noção de posse, universalmente presente nas relações humanas, acaba por se refletir no uso linguístico. São diversos os estudos que têm sido feitos acerca dessa questão sob o aspecto linguístico, havendo uma ampla literatura sobre o assunto, destinada a definir conceitualmente o domínio da posse, explorando diversos aspectos que giram em torno dessa questão (c.f.: NICHOLS, 1988; AIKHENVALD, 2012, por exemplo). As variadas visões acerca da categoria de posse têm levantado, segundo Stassen (2009), a uma série de discussões, que vão desde a relação que esse conceito estabelece com outros até os diferentes mecanismos envolvidos na codificação linguística da posse nas línguas do mundo. Assim, o presente estudo, inicialmente, buscará oferecer um breve panorama sobre a posse sob o viés tipológico, com base em diferentes autores, para, partindo disso, discutir como se dá a expressão de posse predicativa na língua Apurinã, verificando em que medida os fatos dessa língua se aproximam do que há sobre a tipologia acerca desse conceito.

A língua Apurinã pertence à família Aruák, tendo Piro e Iñapari como línguas geneticamente mais próximas. As comunidades Apurinã apresentam uma configuração espacial dispersa, ao longo de vários afluentes do rio Purus, no sudeste do Estado do Amazonas. Em grande parte das comunidades Apurinã apenas os mais velhos falam a língua, o que faz com que esta se encontre, atualmente, ameaçada de extinção. Há alguns estudos antropológicos (por exemplo, SCHIEL, 2004) e linguísticos sobre a língua Apurinã, sendo, entre esses últimos, o de Facundes (2000) o mais completo, em que se encontra uma descrição detalhada da gramática da língua em questão. Há, ainda, outros trabalhos linguísticos descritivos sobre a língua,

\footnotetext{
No presente trabalho, apresenta-se parte dos resultados de uma pesquisa mais ampla sobre posse em Apurinã, que será parte constituinte da Tese de Doutorado da primeira autora deste artigo.
}

entre artigos, dissertações, e outros (por exemplo, FACUNDES, 1995; BRANDÃO, 2006; CHAGAS, 2007; PEREIRA, 2007; LIMA, 2013).

Partindo de Facundes (1995 e 2000), foram selecionadas especificamente informações acerca da codificação linguística da posse em construções verbais da língua Apurinã, às quais foram acrescentadas novas informações, com base em dados recentes, coletados em pesquisas de campo desenvolvidas em novembro de 2014 e abril de 2015, que possibilitaram o desenvolvimento de novas análises, no que concerne à posse predicativa em Apurinã ${ }^{2}$.

\section{Questões teórico-metodológicas}

Espera-se que haja nas línguas em geral formas para expressar predicações tais como 'Eu tenho uma casa'. Nessa construção, a noção expressa revela uma relação de posse envolvendo um determinado verbo, no caso, 'ter', o qual solicita a presença de dois participantes: aquele que 'possui' algo, o possuidor; e aquilo que pertence ao possuidor, ou seja, o item possuído. Segundo Heine (2001), todas as línguas apresentam maneiras de indicar a relação estabelecida entre um determinado item possuído e seu possuidor; e essas relações que envolvem a noção de posse/pertencimento podem apresentar codificações linguísticas distintas, de língua para língua ou mesmo dentro de uma mesma língua. A expressão 'Minha casa', assim como a citada anteriormente, também revela uma relação de posse, embora não mais envolvendo um verbo, e sim nomes.

Os diferentes pontos de vista linguísticos acerca da noção de posse, sob o aspecto tipológico, como já mencionado, dão margem para uma série

2 Os resultados parciais aqui apresentados fazem parte de uma pesquisa maior vinculada ao projeto "Passado e Presente de Povos Aruák: o poder dos Apurinã e Manchineri na Amazônia" (Portaria n Autorização para Ingresso nas Terra Indígenas no 73/AAEP/12 FUNAI, de 3 de dezembro de 2012). 
de discussões a esse respeito, focalizando diversas questões envolvendo a noção de pertencimento, dentre as quais, segundo Stassen (2009), podem ser mencionadas: (i) o relacionamento entre o conceito de posse e outros conceitos; (ii) a relação entre a codificação linguística da posse e alguns aspectos do comportamento extralinguístico; (iii) o conteúdo cognitivo essencial da noção de posse, seus traços caracterizadores; (iv) subtipos semânticos do conceito de posse e seus traços distintivos; (v) as diferentes codificações formais do conceito de posse nas línguas naturais, entre outras. Cada uma dessas questões será brevemente discutida a seguir.

Com relação ao ponto (i), alguns autores questionam se a posse viria a constituir um domínio conceitual independente ou se pertenceria ao domínio da localização. Para Heine (1997, p. 202-207 apud STASSEN, 2009, p.5), posse e localização devem ser vistos como domínios diferentes, embora conceitualmente relacionados. Evidência favorável a essa aproximação entre a noção de posse e outros conceitos encontra-se no fato de a codificação da posse, em diferentes línguas, poder servir para expressar outras noções (aspectuais, modais, expressão de existência, por exemplo). Neste ponto, é relevante dizer que a forma verbal $a w a$, da língua Apurinã, pode significar 'ter', 'viver em/com' ou 'haver', funcionando, respectivamente, como verbo pleno, cópula locativa ou cópula existencial, ilustrando de modo bastante claro o relacionamento entre as noções de posse, localização e existência (mais adiante, serão apresentados dados desses três tipos de ocorrência).

No que se refere à posse e sua codificação nas línguas, item (ii), esta tem sido vista como uma questão de cunho antropológico e político, sendo um conceito basicamente social (MILLER e JOHNSON-LAIRD, 1976 apud STASSEN, 2009); como consequência disso, espera-se que haja certo grau de variação na maneira como esse conceito é compreendido e codificado nas diferentes línguas. Essa compreensão da noção de posse como algo inerentemente sociocultural se baseia na suposição segundo a qual diferentes codificações linguísticas se correlacionam com diferentes crenças ou comportamentos culturalmente estabelecidos ou, inversamente, que diferenças na organização social e desenvolvimento cultural se espelham em diferentes codificações linguísticas (STASSEN, 2009). Em Apurinã, quando da ocorrência de determinados nomes, prototipicamente não possuídos diretamente ${ }^{3}$, é possível visualizar a interferência de fatores socioculturais na codificação da posse; isso pode ser observado no caso da posse de elementos da natureza (animais, plantas, entre outros), por exemplo, como em ny-pyra pathery 'minha criação de galinha' (em que ny- corresponde à $1^{\text {a }}$ pessoa do singular; pyra corresponde à 'criação' e pathery à 'galinha'); tal fato reflete o modo como os falantes dessa língua se relacionam com determinados itens possuídos, sob o aspecto cultural vistos como elementos que, em geral, não são considerados propriedade de alguém, talvez porque os Apurinã entendam que tais elementos, por fazerem parte da natureza, não podem ter um dono.

De acordo com Stassen (2009), em se tratando de (iii), a posse é uma noção relativamente abstrata, difícil de definir explicitamente, mas fundamentada em intuições bastante consistentes. Semanticamente, a posse necessariamente corresponde a uma relação envolvendo duas entidades, o possuidor e o possuído. Como dito anteriormente, o domínio da posse está relacionado semanticamente ao domínio da localização; evidência disso, por exemplo, corresponde ao fato de um dado possuidor e o item possuído, nos casos mais prototípicos de posse, estarem em uma relação locativa relativamente estável. Outro ponto relacionado à caracterização semântica da posse diz respeito ao fato de que em casos de posse a relação entre as duas entidades participantes é assimétrica, em que o papel, ou

Com relação a essa questão, dados da língua demonstram ser possível a expressão de posse direta de animais ou plantas, porém, em contexto pragmático muito específico e pouco usual. 
o status, dos dois participantes é fundamentalmente diferente, tendo o possuidor controle sobre o possuído. Como consequência da admissão do parâmetro "controle" para que se defina a posse semanticamente, tem-se que o possuidor apresentaria o traço [+humano], prototipicamente, já que, em geral, apenas humanos podem exercer controle (STASSEN, 2009).

O que se considera como caso prototípico de posse, no entanto, não reflete as diferentes possibilidades por meio das quais a posse se manifesta nas diversas línguas. Chega-se, assim, ao ponto (iv): há subtipos semânticos dentro do conceito de posse. Distinguem-se, nesse sentido, quatro subtipos de posse: a) posse alienável; b) posse inalienável; c) posse temporária ou física; d) posse abstrata. Stassem (2009) defende que os vários subtipos de posse podem ser caracterizados em termos dos diferentes valores que assumem com base nos parâmetros "contato permanente" (isto é, proximidade espacial e estabilidade temporal) e "controle", tal como ilustrado no quadro abaixo (STASSEN, 2009, p.17, tradução nossa):

Quadro 1 - Traços dos subtipos semânticos de posse

\begin{tabular}{|lcc|}
\hline \multicolumn{1}{|c|}{ Subtipo de Posse } & Contato Permanente & Controle \\
Alienável & + & + \\
Inalienável & + & - \\
Temporária & - & + \\
Abstrata & - & - \\
\hline
\end{tabular}

Na posse alienável, a relação entre possuidor e possuído não é indissolúvel ou inerente; é o caso canônico de posse. Veja-se o exemplo ${ }^{4}$ em Apurinã ${ }^{5,6}$ :

${ }^{4}$ Exemplo proveniente de pesquisa de campo realizada em novembro de 2014.

5 Abreviações utilizadas neste artigo: POSSD = possuído; N.POSSD = não possuído; VBLZ = verbalizador; $\mathrm{PFTV}=$ perfectivo; $\mathrm{SG}=$ singular; $\mathrm{PL}=$ plural; $\mathrm{F}=$ feminino; $\mathrm{M}=$ masculino; $\mathrm{O}=$ objeto; $\mathrm{NPROP}=$ nome próprio; $A S S O C=$ associativo; $P$ PTC = partícula; $E S S=$ essivo; $L O C=$ locativo; $A T R I B=$ atributivo; $D A T=$ dativo; prio; $\mathrm{ASSOC}=$ associativo; $\mathrm{PTC}=$ partícula; $\mathrm{ESS}=$ essivo; $\mathrm{LOC}=$ locativo; $\mathrm{ATR}$
$\mathrm{PERM}=$ permissivo; $\mathrm{ENF}=$ enfático; $\mathrm{GERUND}=$ gerúndio; $\mathrm{ENF}=$ enfático.

6 PERM = permissivo; ENF = enfático; GERUND = gerúndio; ENF = enfático.
6 Fez-se uso da atual ortografia da língua, proposta por Facundes (2000) e posteriormente ajustada pelo mesmo autor. Na ortografia Apurinã, $\mathrm{y}=[\mathrm{i}], \mathrm{x}=[\mathrm{i}], \mathrm{tx}=[\mathrm{ti}], \mathrm{th}=[\mathrm{c}], \mathrm{i}=[\mathrm{j}]$ antes ou depois de vogais na mesma sílaba, mas $\mathrm{i}=[\mathrm{i}]$ nos demais ambientes, e as demais letras correspondem às formas do IPA.
(1) Nuta awa-ry
ny-ãata-re
1SG ter-3SG.M.O 1SG-casco-POSSD

'Eu tenho meu casco (canoa tradicional feita de casca de árvore)'

A propósito do exemplo, é necessário esclarecer que a língua Apurinã, conforme Facundes (2000), além de uma série de pronomes livres, apresenta um conjunto de formas pronominais presas antepostas à base verbal. Tais formas presas, nos verbos, assumem a função de sujeito; quando atreladas a bases nominais, essas formas codificam o possuidor. Em (1) tem-se a forma ny-ãata-re, em que o pronome preso ny-codifica o possuidor; o sufixo -re corresponde a uma marca que ocorre com uma determinada classe de nomes possuídos em Apurinã, classe esta que, numa construção possessiva, exige, além da presença do possuidor, um sufixo de posse. A língua apresenta diferentes classes de nomes possuídos, conforme a marcação que recebem. No caso do sufixo -re, sua ocorrência parece ser lexicalmente condicionada (assunto discutido por FACUNDES (1995), mas que ainda precisa ser aprofundado, e está além do foco do presente artigo, sendo objeto de estudo de FREITAS (em elaboração)).

No mesmo exemplo (1) observa-se a forma verbal $a w a$, codificando o verbo 'ter', à qual se atrela a forma pronominal presa -ry; assim como há uma série de pronomes presos antepostos a bases verbais e nominais para codificar o sujeito/possuidor, também há uma série de pronomes presos, diferentemente dos primeiros, pospostos a bases verbais, codificando o objeto, como no caso de -ry.

Após estes breves esclarecimentos, é possível notar que o exemplo (1) ilustra um caso de posse alienável, em que a relação entre possuidor e possuído não é indissolúvel ou inerente, já que o possuidor, nesse caso, tem controle sobre a relação de posse, podendo desfazê-la quando desejar; há no exemplo tanto a expressão de posse predicativa, em que figura a forma 
verbal awa, 'ter', quanto a expressão de posse atributiva (nominal, a qual não será focalizada no presente artigo).

Já a posse inalienável diz respeito, prototipicamente, a relações de posse que envolvem partes do corpo e termos de parentesco, mas incluindo, em algumas línguas, relações parte-todo, relações sociais, objetos da cultura material ou os agentes ou pacientes de uma ação (SEILER, 1983 apud STASSEN, 2009). Diferencia-se da posse alienável por não envolver controle do possuidor sobre o possuído, já que as pessoas não são capazes de determinar o que pode vir a ocorrer com as partes de seu corpo ou com membros da família, tampouco podem diluir a relação estabelecida por sua própria vontade. No que se refere ao parâmetro "contato permanente", fica evidente a proximidade espacial e a estabilidade temporal dos inalienáveis prototípicos, já que, em circunstâncias normais, uma pessoa não pode se separar de uma parte de seu corpo ou deixar de ser um membro da sua família enquanto existir (STASSEN, 2009). Os exemplos a seguir ilustram a posse inalienável em Apurinã:

(2) a. [Hãtaku-ru yny-ru] menina-F mãe-F 'Mãe da menina'

b. [Kema kywy] Mipa atama-ta anta cabeça.de NPROP ver-VBLZ

'Mipa viu a cabeça da anta'

Nos dois casos acima, a relação de posse é inalienável, isto é, prototipicamente indissolúvel. Em (2a) observa-se a ocorrência de ynyru, 'mãe' que, em Apurinã, corresponde a um nome obrigatoriamente possuído, assim como os demais termos de parentesco da língua, podendo ocorrer apenas quando da expressão de um possuidor? ${ }^{7}$. A construção kema kywy,

7 Exceção a essa regra se dá nos casos de vocativo, em que o falante é interpretado como possuidor. 'cabeça da anta', em (2b), embora expressando posse inalienável, apresenta comportamento diferente do primeiro caso (exemplo 2a), já que partes do corpo, na língua em questão, podem aparecer em sua forma não possuída, em contextos pragmáticos específicos (por exemplo, kywĩ-txi, 'cabeça' - em que $k y w y^{8}$ corresponde à cabeça e -txi diz respeito a um sufixo que marca a forma não possuída de uma determinada classe de nomes em Apurinã).

Casos de posse temporária ou física, de acordo com Stassen (2009), definemse em termos da disponibilidade de algo para alguém, em algum ponto na escala temporal, não sendo relevante se o possuidor é de fato dono ou não do objeto temporariamente possuído. 0 contato entre possuidor e possuído é normalmente visto como acidental, não permanente, durando um tempo determinado; enquanto a relação de posse durar, o possuidor exerce controle sobre o item possuído. 0 excerto abaixo ilustra um caso de posse temporária em Apurinã, retirado de diálogo presente em material de conversação na língua9:

(3) Kamasaru ${ }^{10}$

$\begin{array}{lll}\text { Ĩthepary } & \text { ximaky? } & \text { 'Cadê o peixe?' } \\ \text { cadê } & \text { peixe }\end{array}$

Aramakary ${ }^{11}$ :
Kuna ka-iumaã-nu.
'Não peguei nada.'

não ATRIB-pegar-1SG.O

Yny umitika-ry ximaky. 'A lontra espantou os peixes.'

lontra espantar-3SG.M.O peixe

Inhinhĩã kuna minhakaty n-uka. 'Por isso que não matei nada.'

por.isso não nada 1SG-matar

${ }^{8}$ Em kywy ocorre um processo de anteriorização de $y$, passando a $i$, e sua nasalização, quando diante da consoante palatal do morfema seguinte, daí a última vogal de kywy passar a /î/quando diante de

9 - ${ }^{-}$Material intitulado "Amu Asãkirewata Pupỹkary Sãkire", elaborado por Facundes e equipe, ainda não publicado.

publicado.
${ }_{10}$ Nome de pessoa em Apurinã.

${ }^{11}$ Nome de pessoa em Apurinã. 
Kamasaru:

Atha-munhi awa ximaky. 'Nós temos peixe.'

1PL-DAT haver peixe

Ximaky p-anhik-inha-wa.

'Pode levar o peixe.'

Em Atha-munhi awa ximaky observa-se que a relação de posse é temporária, uma vez que se sinaliza, no texto, a possibilidade de transferência para outrem, em que se tem a intenção não de informar a posse do peixe, mas sim de oferecê-lo ao interlocutor.

Na posse abstrata o item possuído não é um objeto físico, o que pode ser visto em (4). Esse tipo de posse se distancia sobremaneira da noção de propriedade, o que faz com que alguns duvidem de que este seja realmente um caso de posse. A noção de controle entre possuidor e possuído está claramente ausente. Eventos desse tipo podem ser caracterizados, pelo menos prototipicamente, como não permanentes, referindo-se a estados físicos ou mentais de natureza transitória (STASSEN, 2009). Há em Apurinã exemplos ${ }^{12}$ desse tipo de ocorrência, como ilustrado abaixo. Mais adiante, outros exemplos serão apresentados, focalizando construções verbais em que a posse se manifesta em Apurinã.

(4) a. Ny-neenama

1SG-valentia

'minha valentia'

b. Ny-pinike

1SG-vingança

'minha vingança'

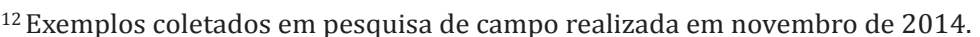

c. Ithapu awa-ry

sono haver-3SG.M.O

'Ele tem sono'

O espaço conceitual da posse e seus subdomínios são universalmente válidos; no entanto, como dito anteriormente, a codificação linguística desse espaço varia de língua para língua, o que conduz ao item (v), voltado para as diferentes codificações formais do conceito de posse nas línguas naturais. Em Apurinã, por exemplo, há, em construções possessivas nominais, diferentes marcações morfológicas que permitem agrupar os nomes em diferentes classes, como dito anteriormente, além de haver mais de uma forma verbal que envolve a expressão de posse na língua.

Embora essa diversidade de modos para a marcação de posse nas línguas do mundo possa dificultar uma descrição linguística abrangente referente ao domínio da posse, há características principais dentro desse domínio que parecem se refletir em todas as línguas (HEINE, 1997 apud PERNISS e ZESHAN, 2008). Sintaticamente, conforme Perniss e Zeshan (2008), todas as línguas distinguem entre construções de posse predicativa (ou verbal) e atributiva (ou nominal). Prototipicamente, a posse predicativa ocorre em construções verbais por natureza, em que o possuidor e o possuído ocupam o papel de argumentos do predicado. Os autores destacam dois principais tipos de posse predicativa: have-construction e belong-construction.

As duas construções diferem em certos aspectos, que vão além da escolha do verbo. Essas diferenças incluem o tipo de argumento que possuidor e possuído codificam, a definitude dos elementos nominais (a house; the house) e o status informacional dentro da sentença. Construções usando ter (have) tipicamente enfatizam o possuidor, o que é evidenciado pelo papel de sujeito desempenhado por esse elemento e pelo fato de o elemento possuído apresentar-se indefinido. Em contraste, construções utilizando pertencer 
(belong) são tipicamente caracterizadas por um elemento possuído definido, exercendo papel de sujeito, sendo este focalizado na sentença (ZESHAN e PERNISS, 2008).

Os autores (op. cit.) afirmam, ainda, que nem todas as línguas apresentam dois verbos independentes que correspondam a have e a belong do inglês (ou ter e pertencer do português), cujas construções em que figuram apresentam entre si diferenças semânticas e sintáticas, além daquelas em termos de referência semântico-pragmática (HEINE, 1997 apud ZESHAN e PERNISS, 2008). Então, a construção usada em uma língua para expressar canonicamente o equivalente a "I have a house" é considerada para exemplificar sua have-construction, seja no caso de a língua usar um verbo significando "ter"; ou um verbo significando "take" (tomar, levar, apanhar); ou um verbo cópula junto com a marcação de caso locativo; ou uma construção sem verbo algum.

Em termos de estrutura linguística, segundo Perniss e Zeshan (2008), construções de posse predicativa contrastam com as construções de posse atributiva. A posse atributiva pode ser observada em construções do português como: (i) "meu livro" e (ii) "livro do João", ou do inglês como: (iii) "my book" ou (iv) "John's book", em sintagmas nominais. Esses exemplos mostram a possibilidade de um relacionamento possessivo pronominal, em que o possuidor é um pronome (nos casos de (i) e (iii)), ou de uma relação nome-nome (nos casos de (ii) e (iv)), em que o possuidor é um nome (João e John). Em termos de classificação tipológica, a posse atributiva focaliza a maneira como a ligação entre os dois nominais (possuidor e possuído) é estabelecida e a ordem desses elementos (HEINE, 1997 apud PERNISS e ZESHAN, 2008).

Assim, o possuidor e o possuído podem estar relacionados um ao outro por meio de simples justaposição ou concatenação (como no inglês "book page”, 'página do livro'), mas também por meio de marcas morfológicas adicionais (como no caso de "John's book", citado acima) em qualquer um ou ambos os elementos (cf. CROFT, 2002 apud PERNISS e ZESHAN, 2008). Comparada à posse predicativa, a qual é mais suscetível a exprimir uma relação de posse dada como "certa", inequívoca, construções possessivas atributivas geralmente aludem a uma relação possessiva suposta (uma possibilidade).

Adicionalmente, Heine (1997 apud PERNISS e ZESHAN, 2008) considera que as construções possessivas atributivas podem expressar uma gama mais ampla de significados possessivos, em comparação às construções de posse predicativa. Além de posse permanente e temporária, construções possessivas atributivas podem expressar outros tipos de relações de posse, incluindo posse abstrata, bem como relações que não são estritamente possessivas (ex: “Carro da Maria”, como o carro que a Maria estava pensando em comprar, mas que, de fato, nunca comprou).

Em Apurinã, como já dito, ocorre tanto a posse predicativa quanto a atributiva. Em se tratando da primeira, a língua apresenta formas verbais tais como awa 'ter, haver, viver em/com', ithu 'ter muito', além de $n a=(h)$ ãty 'ter muito' (literalmente significando 'não ter só um', em que na= é uma forma clítica do termo kuna 'não' e (h)ãt-y/ (h)ãt-u se refere ao numeral 'um', 'uma', respectivamente, havendo uma variação dialetal, em que em algumas localizadas utiliza-se a forma com o /h/ e em outras sem o $/ \mathrm{h} /$ ) que codificam essa noção, tendo sido estas duas últimas (ithu e $n a=(h) a ̃ t y /$ $n a=(h) a ̃ t u)$ atestadas em pesquisa de campo realizada em 2014, nunca antes descritas. No que se refere à posse atributiva, a língua apresenta diferentes possibilidades de codificação e uso, conforme Facundes (1995 e 2000), as quais não serão focalizadas no presente artigo, cujo escopo corresponde apenas às construções de posse predicativa.

Pretendeu-se, nesta seção, mostrar que todos os tipos semânticos apresentados por Stassem (2009) são encontrados em Apurinã. 


\subsection{Dados da pesquisa}

Alguns dados e a análise inicial utilizados neste artigo encontram-se em Facundes (1995 e 2000). De forma a ampliar o corpus da língua em análise, são utilizados outros dados, atestados em textos, em questionários lexicais coletados e armazenados em um banco de dados eletrônico, além de dados coletados em pesquisas de campo mais recentes.

\subsection{Coleta, seleção e apresentação dos dados}

Foram selecionados dados relativos a construções de posse predicativa em Apurinã, obtidos nas fontes de pesquisa mencionadas acima: Facundes (1995 e 2000); banco de dados textuais e lexicais organizado por Facundes e sua equipe da Universidade Federal do Pará, além daqueles coletados em pesquisas de campo desenvolvidas em novembro de 2014 e abril de 2015, em diferentes comunidades Apurinã localizadas em duas terras indígenas, Tumiã e Acimã, e também na cidade de Lábrea, Amazonas. Durante a coleta de dados, colaboradores falantes da língua Apurinã forneceram informações relativas a construções possessivas, com o auxílio de questionários de elicitação de sentenças previamente elaboradas em língua portuguesa, em que se solicitou ao colaborador a forma correspondente em Apurinã. Os dados coletados em campo foram anotados conforme a ortografia em uso da língua.

Tendo em vista que o fenômeno foco deste estudo se dá no âmbito de construções verbais, a seguinte seção abordará, de modo sucinto, algumas das principais propriedades de verbos em Apurinã, para que se possa compreender melhor a posse predicativa na língua em questão.

\section{Breve caracterização dos verbos em Apurinã}

Em Apurinã, os verbos admitem morfemas presos exclusivamente verbais, podendo receber, ainda, morfemas que ocorrem fora da morfologia inerentemente verbal. No verbo reside a estrutura morfológica mais complexa da língua, sendo que bases verbais podem admitir prefixos e sufixos, embora a morfologia verbal seja predominantemente sufixal. As marcas pronominais de sujeito e marcas pronominais de objeto se ligam a bases verbais ${ }^{13}$, sendo que a marca pronominal de sujeito vem anteposta à base verbal, enquanto que a marca pronominal de objeto vem posposta à base verbal. Essas marcas podem ocorrer, atreladas às bases verbais, como elementos correferenciais ao sujeito gramatical e/ou ao objeto gramatical da sentença expressos por formas verbais livres em posição pós-verbal. As propriedades gramaticais e semânticas de verbos motivam o surgimento de subcategorias verbais (definidas por FACUNDES (2000) e, posteriormente, parcialmente reclassificadas por CHAGAS (2007)). Além dos verbos simples, a língua apresenta alguns poucos casos de verbos compostos e também casos de verbos com nomes incorporados, mas apenas os verbos simples serão focalizados, uma vez que o fenômeno apresentado neste artigo se dá no nível dos verbos simples, ou seja, não há verbos de posse compostos ou nomes incorporados em verbos de posse. A classificação proposta pelos autores envolve diferentes categorias de verbos, dentre as quais se optou, para os propósitos do presente trabalho, destacar as seguintes:

a) Verbos transitivos regulares: são os transitivos mais típicos, que envolvem a presença de dois argumentos, sujeito e objeto, operando em um sistema nominativo/acusativo, conforme exemplo e esquema a seguir: no esquema, $A$ = sujeito de verbo transitivo; $S=$ sujeito de verbo intransitivo. $\mathrm{S}$ sofre uma cisão, dando origem a $\mathrm{Sa}=$ sujeito

${ }^{13}$ Facundes (2000) atestou a existência de duas séries de pronomes na língua Apurinã: os livres e os presos, como já sinalizado anteriormente no presente artigo. As formas presas são aqui chamadas de marcas pronominais. 
de verbo intransitivo não descritivo ou sujeito de verbo intransitivo descritivo subjetivo (no caso da língua Apurinã, essas duas categorias de verbos se alinham), e So = sujeito de verbo intransitivo descritivo objetivo; $\mathrm{O}=$ objeto direto de verbo transitivo.

(5) U-atamata-ry ywa sytu 3SG.F-ver-3SG.M.O 3SG.M mulher 'A mulher, ela o viu'

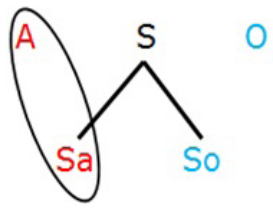

No exemplo (5), verifica-se a ocorrência das marcas pronominais de sujeito, prefixal, e objeto, sufixal, presas à base verbal atamata, as quais são correferenciais, respectivamente, ao sujeito gramatical, sytu 'mulher', e ao objeto gramatical, ywa 'ele', da sentença. Como o nome sytu e o pronome livre $y w a$ vêm após o verbo, ocorre a marcação de correferencialidade no verbo (uma vez que esta só ocorre caso as formas livres do sujeito e/ou objeto gramatical correferenciais sejam pós-verbais. As marcas pronominais presas de sujeito e objeto também podem ocorrer sem a expressão obrigatória de um sujeito e/ou objeto gramatical correferencial).

b) Verbos intransitivos não descritivos: requerem um argumento único codificando o sujeito e operando em um sistema nominativo/ acusativo, conforme exemplo e esquema abaixo:

(6) Y-myteka kyky

3SG.M-correr homem

'O homem corre'

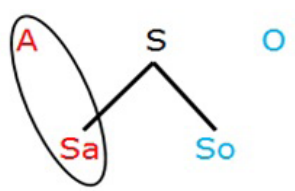

c) Verbos intransitivos descritivos subjetivos14: também requerem apenas o argumento sujeito, expressando estados transitórios. Operam em um sistema nominativo/acusativo:

(7) Ny-sãpaka nuta

1SG-estar.cansado $1 \mathrm{SG}$

'Eu estou cansado'

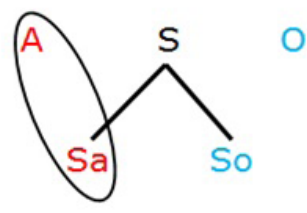

d) Verbos intransitivos descritivos objetivos: requerem um argumento único sujeito, designando estados permanentes e operando em um sistema ergativo/absolutivo, em que um sujeito intransitivo se alinha ao objeto de verbo transitivo, diferindo de A e de Sa:

\section{(8) Hareka-nu ser.bom-1SG.O}

'Eu sou bom'

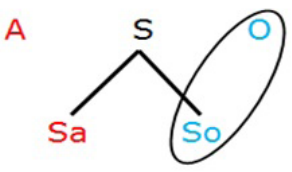

Em (8), muito embora seja codificado por um pronome preso posposto à base verbal hareka, o argumento So na primeira pessoa do singular, -nu 'eu', é expresso morfologicamente como objeto de verbo transitivo, resultado de uma cisão que ocorre em verbos intransitivos da língua Apurinã, gerando os intransitivos descritivos subjetivos (cujo argumento único vem codificado sob a forma de uma marca pronominal presa de sujeito, quando da utilização da série de pronomes presos) e os intransitivos descritivos objetivos (cujo

${ }^{14}$ Os rótulos Intransitivo descritivo subjetivo e Intransitivo descritivo objetivo foram dados por Facundes (2000) unicamente pelo fato de sujeitos desses verbos serem codificados, respectivamente, por marcas pronominais presas de sujeito e de objeto. 
argumento único vem codificado sob a forma de uma marca pronominal presa de objeto, quando da utilização da série de pronomes presos), cisão esta condicionada pelo traço léxico-semântico permanente/transitório.

Feito este breve recorte, a fim de ilustrar minimamente como se comportam, de modo geral, os verbos na língua Apurinã, a seção seguinte se volta para a caracterização da posse em construções verbais da língua em questão.

\section{Construções de posse predicativa em Apurinã}

Em construções de posse predicativa, como dito anteriormente, a língua conta com a forma verbal awa que, entre outros significados, corresponde a 'ter', descrita inicialmente por Facundes (2000); além das formas ithu, 'ter muito' e $n a=(h) \tilde{a} t-y / n a=(h) \tilde{a} t-u$ 'ter muito' (masculino e feminino, respectivamente), atestadas em pesquisas de campo mais recentes e nunca antes descritas. Cada uma dessas três formas verbais relacionadas à expressão de posse em Apurinã será descrita e exemplificada a seguir.

A forma verbal $a w a$, na língua Apurinã, assume, pelo menos, três funções: cópula existencial, cópula locativa e verbo pleno "ter", como já havia descrito em Facundes (2000). Esse comportamento de awa fornece evidências claras da relação estabelecida entre as noções de posse, localização e existência, amparadas pelos pressupostos de autores como Stassen (2009), entre outros, como visto anteriormente. Aqui, dar-se-á ênfase aos casos em que tal forma verbal codifica o conceito "ter"; porém, a título de exemplificação, observem-se os exemplos ${ }^{15}$, a seguir, de outro tipo de ocorrência de $a w a$.

${ }_{15}$ Exemplos coletados em pesquisa de campo desenvolvida em novembro de 2014.
(9) a. Pitha awa-ry nhipukury? 2SG ter-3SG.M.O comida
'Você tem comida?'
b. Kuna awa-ry
Não haver-3SG.M.O
'Não tem (comida)'
c. Katarukyry aw-inhi?
farinha haver-GERND
'Tem farinha?' Lit.: 'Há farinha?'

Em (9b) a forma verbal awa exprime a noção de existência, funcionando como cópula existencial, não como verbo pleno 'ter', o que também ocorre em 9(c), diferentemente da ocorrência de awa do exemplo (9a).

Os exemplos ${ }^{16}$ em (10), abaixo, ilustram uma outra ocorrência da forma verbal $a w a$, como cópula locativa:

$$
\begin{aligned}
& \text { (10) a. } \text { ny-wãka-ty-kata } \\
& \text { 1SG-xará-grande-ASSOC } \\
& \text { 'Eu vivo com meu xará' } \\
& \text { b. } \text { ywã-ra atha wai awa-pe-ru } \\
& \text { PTC-ESS 1PL aqui viver-PFTV-3M.O } \\
& \text { 'Então ficamos aqui' }
\end{aligned}
$$

Em (10a) e (10b) apresentam-se casos de awa como cópula locativa, expressando 'viver em/com', 'habitar', 'residir', 'morar'. Nesse tipo de ocorrência, a forma verbal awa pode apresentar dois argumentos, sendo que o primeiro é marcado como sujeito e o segundo como objeto, mas é um locativo e é estruturalmente opcional na oração (exemplo 10b).

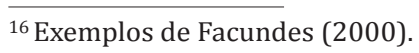


Finalmente, temos a ocorrência de awa como verbo pleno 'ter', conforme exemplos ${ }^{17}$ abaixo:

(11) a. Nuta awa epi ithary 1SG ter dois irmão

'Eu tenho dois irmãos'

b. Pitha awa-ry nhipukuri?

2SG ter-3SG.M.O comida

'Você tem comida?'

c. Nuta kuna awa-ry ximaky

1SG não ter-3SG.M.O peixe

'Eu não tenho peixe'

d. n-awa-ry epi kanawa

1SG-ter-3M.O dois canoa

'Eu tenho duas canoas'

e. Pitha awa-ry xaminaky?

2SG ter-3SG.M.O espingarda

'Você tem espingarda?'

Observa-se, com base nos exemplos ilustrados em (11), que awa, funcionando como 'ter', pode ocorrer sem nenhum prefixo ou sufixo, como em (11a), ou pode carregar prefixos e sufixos verbais, tais como as marcas de sujeito e objeto ( $11 \mathrm{~b}, \mathrm{c}, \mathrm{d}, \mathrm{e})$, entre outros morfemas exclusivamente verbais. Comporta-se como verbo transitivo regular. Na língua, a expressão de negação de posse se faz por meio da utilização do termo kuna, 'não', (exemplo 11c), em que não se observa uma forma verbal independente para codificar a noção de 'não posse'.

$\overline{{ }^{17} \text { Exemplos de (11a) a }}$ (11e) coletados em pesquisa de campo desenvolvida em novembro de 2014.
Adicionalmente à forma verbal $a w a$, constatou-se, em recentes pesquisas de campo, a ocorrência da forma ith $u^{18}$, significando 'haver muito', no sentido existencial, ou 'ter muito', expressando posse, pertencimento. Esta última ocorrência de ithu, como verbo pleno ter, foi atestada em abril de 2015, durante a mais recente pesquisa de campo realizada. Os dados ${ }^{19}$ a seguir ilustram essas ocorrências:
(12) a. Ithu-pyty-i
[hĩtha] ${ }^{\text {So }}$
haver.muito-ENF-2PL.O 2PL

'Vocês são muitos mesmo' Lit.: 'Há muitos de vocês'
b. Ithu-pyty-ry $\quad[x i m a k y]^{\text {So }}$ wyny-ã haver.muito-ENF-3SG.M.O peixe rio-LOC

'Tem muito peixe mesmo no rio' Lit.: 'Há (existe) muito peixe no rio'

c. Ithu-ru [ikiiana] ${ }^{\text {So }}$ watxa

haver.muito-3SG.F.O comida hoje

'Tem futuro'. Lit.: 'Há (existe) muita comida hoje'

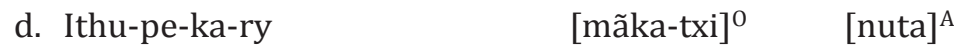 ter.muito-PFTV-PRED-3SG.M.O roupa-N.POSSD 1SG 'Eu já tenho muita roupa'
e. [Nuta] $^{\mathrm{A}}$ ithu-panhi-ka-ry [ny-nyrymany-waku-ry] ${ }^{0}$ 1SG ter.muito-IMPFTV-PRED-3SG.M.O 1SG-parente-PL-M 'Eu tenho muitos parentes' Lit.: 'Eu tenho muitos meus parentes'

f. $[\text { Kyky }]^{\mathrm{A}}$ ithu-panhi-ka-ku $\quad[\text { xiripi-txi }]^{0}$ homem termuito-IMPFTV-PRED-FUT flecha-N.POSSD

'O homem vai ter muita flecha ainda'

${ }^{18}$ Forma atestada no Tumiã, no Acimã e na cidade de Lábrea.

${ }^{19}$ Dados coletados durante duas pesquisas de campo, desenvolvidas em novembro de 2014 e em abril de 2015. 
Nos exemplos em (12a-c) a forma ithu, semanticamente, expressa noção existencial, adicionada à ideia de intensificação, grande quantidade, referindose a 'haver muito', 'existir muito'. Em tais exemplos, respectivamente, hĩtha 'vocês', ximaky 'peixe' e ikiiana 'comida' correspondem àquilo que se afirma existir. Em se tratando de estrutura argumental, o argumento único requerido por ithu com sentido existencial 'haver muito' é codificado da mesma forma que objetos diretos de construções transitivas, revelando que, nesse tipo de construção, ithu se comporta como verbo intransitivo descritivo objetivo, o que pode ser verificado pelas marcas pronominais presas de objeto, atreladas à ithu, concordando com os sujeitos gramaticais das sentenças em (12a-c).

Em (12d-f) observam-se diferenças tanto semânticas quanto morfossintáticas com relação aos exemplos vistos em (12a-c); isto porque, semanticamente, exprimem-se, nos exemplos de d-f, relações de posse, pertencimento (alienável em (12d) e (12f); inalienável em (12e)). Quanto ao aspecto morfossintático, esses últimos exemplos revelam a presença, cada um deles, de dois argumentos requeridos por ithu: um sujeito transitivo (nuta 'eu', em (12d-e) e kyky 'homem', em (12f)); e um objeto (mãkatxi 'roupa'(12d); nynyrymanywakury 'meus parentes' (12e) e xiripitxi 'flecha' (12f)), o sujeito codificando o possuidor e o objeto codificando o item possuído.

Na base da forma ithu recaem morfemas inerentemente verbais; além de marcas como - pyty, exemplo (12a), denotando uma noção aspectual, também ocorre com as marcas pronominais presas de objeto. A negação dessa forma verbal se dá nos mesmos moldes de $a w a$, isto é, por meio do termo kuna 'não' diante do verbo em questão (por exemplo Kuna ithu-ry nhipukury 'Não tem muita comida', em que kuna = não; ithu = 'haver muito'; $-r y=3$ SG.M.O e nhipukury ${ }^{20}=$ comida).

${ }^{20}$ As formas ikiiana e nhipukury são, possivelmente, casos de variantes geográficas, ambas significando 'comida', 'alimento', tendo sido fornecidas por colaboradores de comunidades Apurinã distintas.
Outra forma semanticamente relacionada a ithu e, consequentemente, à expressão de posse em Apurinã, também foi atestada em pesquisa de campo. Observem-se os exemplos:
(13)
$[\text { kãkiti }]^{\text {So }}$
não=haver.um-3SG.M.O gente
'Tem muita gente' Lit.: 'Não há só uma pessoa'
b. Na=ãty-wa [athe] ${ }^{\text {So }}$
não=haver.um-1PL.O 1PL
'Tem muitos de nós' Lit.: 'Não há só um de nós'

A forma (h)ãt-y/ (h)ãt- $u^{21}$, masculino e feminino, respectivamente, corresponde ao numeral "1" em Apurinã ou ao artigo indefinido (em algumas comunidades usado sem o /h/, ficando ãty/ ãtu). Porém, nos exemplos em (13) a mesma forma apresenta comportamento tipicamente verbal, funcionando tal como verbos intransitivos descritivos objetivos, ou seja, da classe de verbos intransitivos cujo único argumento é marcado com a forma pronominal presa de objeto atrelada ao verbo (concordando com o sujeito gramatical, no caso kãkiti 'gente' (13a) e athe 'nós' (13b)) - diferentemente dos verbos descritivos subjetivos que são marcados pela forma pronominal presa de sujeito (FACUNDES 2000, CHAGAS 2007) - podendo ocorrer com o clítico simples na= (exemplo 13a-b), uma redução fonológica do termo kuna, que corresponde à negação na língua. Na realidade, a forma hãt-y/ hãt-u, quando verbal, só adquire sentido de "haver muito" se articulada à negação; essa articulação entre a negação e a forma hãty/hãtu (esta última acrescida

${ }^{21}$ Forma com /h/ atestada na Terra Indígena Tumiã. Nesse caso, o uso de /h/ na língua Apurinã parece ser condicionado por fatores geográficos. Atualmente, esse e outros casos de variação em Apurinã estão sendo tratados em uma dissertação de mestrado, orientada por Facundes. 
de marcas pronominais presas de objeto) é que gera o sentido de "haver muito" que, literalmente, significa "não haver só um".

Nos exemplos em (13), a noção expressa pela forma verbal é existencial, não propriamente possessiva; no entanto, nos dados coletados foram atestados exemplos da forma na=(h)ãty/na=(h)ãtu ocorrendo como verbo pleno "ter muito", isto é, posse adicionada à noção de intensificação, quantidade, conforme exemplos a seguir:

$$
\begin{aligned}
& \text { (14) a. }[\text { Hÿtha }]^{A} \text { na=ãty-ry } \quad[\text { nhipukury }]^{0} \\
& \text { 2PL não=ter.um-3SG.M.O comida } \\
& \text { 'Vocês têm muita comida' } \\
& \text { b. }[\text { Sytu }]^{\mathrm{A}} \text { na=ãtu-ru } \quad \text { [amaryte }^{\mathrm{O}} \\
& \text { mulher não=ter.um-3SG.F.O filho, criança } \\
& \text { 'A mulher tem muitos filhos' } \\
& \text { c. }[\mathrm{Uwa}]^{\mathrm{A}} \text { na=ãtu-ru } \quad[\text { kapĩkare }]^{\mathrm{O}} \\
& \text { 3SG.F não=ter.um-3SG.F.O medo } \\
& \text { 'Ela tem muito medo' } \\
& \text { d. }[\text { Kyky }]^{\mathrm{A}} \text { na=ãty-ry } \quad \text { [dĩnhẽru }^{\mathrm{O}} \\
& \text { homem não=ter.um-3SG.M.O dinheiro } \\
& \text { 'O homem tem muito dinheiro' } \\
& \text { e. }\left[\text { Atha } { } ^ { \mathrm { A } } \text { na=ãty-ry } \quad \left[\text { dĩnhẽru }{ }^{\mathrm{O}}\right.\right. \\
& \text { 1PL não=ter.um-3SG.M.O dinheiro } \\
& \text { 'Nós temos muito dinheiro' }
\end{aligned}
$$

Nos exemplos em (14), além do argumento sujeito (nos casos em questão sempre codificado por um pronome livre ou por um nome), a construção verbal $n a=\tilde{a} t y / n a=\tilde{a} t u$ solicita a presença da marca pronominal presa de objeto; essa marca de objeto concorda com o outro argumento requerido pela construção, respectivamente (em (14) de (a) até (e)), nhipukury 'comida', amaryte 'filho', kapĩkare 'medo' e dĩnhẽru 'dinheiro' (nos dois últimos exemplos). Desta feita, $n a=\tilde{a} t y / n a=\tilde{a} t u$ comporta-se tal como verbos transitivos típicos. É interessante notar que até mesmo com noções abstratas (exemplo 14c) a forma verbal em questão, articulada à negação, funciona com sentido de "ter muito".

Um caso interessante da ocorrência de $n a=(h) \tilde{a} t y / n a=(h) \tilde{a} t u$ pode ser visto no exemplo a seguir:
(15) Kuna na=ãty-ry aãmyna-ã txipukury não não=haver.um-3SG.M.O árvore-LOC fruta 'Não tem muita fruta na árvore'

No exemplo (15) verifica-se a presença de dupla negação, uma vez que a construção verbal em questão, significando literalmente "não ter só um", inerentemente pressupõe a presença da negação e, para negá-la, portanto, faz-se necessária a presença de outra negação, agora não mais sob a forma de um clítico (uma vez que a posição do clítico, diante do verbo, já está ocupada).

\section{Considerações finais}

Partindo da literatura tipológica sobre a categoria de posse, buscou-se traçar um panorama da expressão de posse predicativa na língua Apurinã para, em seguida, com base em Facundes (1995 e 2000), em informações do banco de dados textuais e lexicais e em pesquisas de campo recentes, apresentar uma breve caracterização da língua sob esse aspecto.

Em construções de posse predicativa, além da forma verbal awa funcionando como verbo pleno 'ter' (descrita anteriormente por FACUNDES, 2000), foram atestadas outras formas verbais semanticamente relacionadas a esta: 
(a) ithu, 'ter muito', que se comporta como verbo intransitivo descritivo objetivo e como verbo transitivo típico, denotando 'ter muito', no sentido de posse, pertencimento;

(b) $n a=(h) \tilde{a} t y / n a=(h) \tilde{a} t u$, masculino e feminino, respectivamente, também com sentido de "ter muito", mas literalmente significando "não ter só um", já que se relaciona com o numeral (h)ãty/(h)ãtu 'um' da língua Apurinã. Foram atestados exemplos dessa ocorrência tanto como verbo pleno "ter muito", expressando a noção de posse propriamente dita, nesse caso, requerendo os argumentos sujeito e objeto, comportando-se, portanto, como os verbos transitivos típicos; bem como sua ocorrência com sentido existencial, atrelando-se a uma marca pronominal de objeto, aproximando-se de verbos intransitivos descritivos objetivos.

As discussões tecidas por Stassen (2009), Heine (2001), bem como por Perniss e Zeshan (2008), no que concerne à categoria de posse, parecem refletir muitos dos fenômenos que ocorrem na língua Apurinã, em se tratando da caracterização semântica e codificação linguística dessa noção. No que concerne aos subtipos semânticos de posse apresentados por Stassen, poder-se-ia propor a existência de mais um, com base nos dados atestados na língua Apurinã; além da posse alienável, inalienável, temporária e abstrata, ocorre em Apurinã o que se optou por chamar de "posse quantificada", uma vez que a expressão de posse predicativa em determinados casos com as formas ithu e na=(h)ãty/na=(h)ãtu está indissoluvelmente ligada à quantificação, podendo ser traduzida como 'ter muito'.

Assim sendo, com base em dados inéditos coletados em recentes pesquisas de campo, foi possível agregar aos dados e análises já existentes informações acerca da categoria de posse em Apurinã. Apesar de alguns dos resultados apresentados ainda serem preliminares, acredita-se que estes contribuam de forma importante para a descrição e análise da língua
Apurinã, assim como para a tipologia geral sobre a marcação de posse nas línguas do mundo.

\section{Referências}

AIKHENVALD, Alexandra. Possession and Ownership: A Cross-Linguistic Perspective. In: Aikhenvald, Alexandra \& R. M. W. Dixon (eds.). Possession and Ownership. Oxford University Press, 2012. p. 1-64. http://dx.doi.org/10.1093/acprof:oso/9780199660223.001.0001

BRANDÃO, Ana Paula Barros. Dicionário de Fauna e Flora Apurinã. Belém, Pará: Universidade Federal do Pará, 2006 (Trabalho de Conclusão de Curso).

CHAGAS, Angela Fabíola Alves. Aspectos Semânticos, Morfológicos e Morfossintáticos das Palavras Descritivas Apurinã. Belém, Pará: Programa de Pós-graduação em Letras - Mestrado em Estudos Linguísticos da Universidade Federal do Pará (Dissertação de Mestrado), 2007.

FACUNDES, Sidi. Possession and Unpossession in Apurinã (Maipuran). In: LSA Parassession: Languages South of Rio Bravo. Nova Orleans. Conference Proceedings of LSA Parassession: Languages South of Rio Bravo, 1995

The Language Of The Apurinã People Of Brazil (Maipure/Arawak). Nova York, Búfalo: Faculty of the Graduate School of State University of New York at Buffalo (Tese de Doutorado), 2000.

FREITAS, Marília Fernanda Pereira de. A Categoria de Posse na Língua Apurinã (Aruák). Belém: Universidade Federal do Pará, em elaboração.

HEINE, Bernd. Ways of explaining possession. In: BARON, Irene; HERSLUND, Michael; SøRENSEN, Finn (eds.). Dimensions of Possession. Amsterdã, Filadélfia: John Benjamins Publishing Company, 2001. p. 311-328.

LIMA, Bruna Fernanda Soares de. Variação e Mudança: o duplo vocabulário da língua Apurinã. Belém, Pará: Universidade Federal do Pará - Faculdade de Letras, 2013. (Trabalho de Conclusão de curso).

NICHOLS, J. On alienable and inalienable possession. In SHIPLEY, W. (ed.). In honor of Mary Haas (from The Haas Festival Conference on Native American Linguistics). Mouton de Gruyter: Berlin, New York/Amsterdam, 1988. p. 557-609.

PEREIRA, Érica Lúcia Barreto. Variação em Apurinã: aspectos linguísticos e fatores condicionantes. Belém, Pará: Programa de Pós-graduação em Letras - Universidade Federal do Pará, 2007. Dissertação de Mestrado. 
PERNISS, Pamela; ZESHAN, Ulrike (eds.). Possessive and Existential Constructions: introduction and overview. 2008. p. 1-31.

STASSEN, Leon. Predicative Possession. New York: Oxford University Press, 2009.

SCHIEL, Juliana. Tronco velho: histórias Apurinã. Campinas, SP: [s.n.], 2004. Tese (Doutorado) - Universidade Estadual de Campinas, Instituto de Filosofia e Ciências Humanas.

Recebido em 16/04/2015

Aceito em 21/06/2015 